\title{
O rosto de Saddam Hussein: um estudo de caso
}

\author{
Orleães Alan Mendonça FURTADO \\ (Universidade do Vale do Rio dos Sinos)
}

RESUMO: o artigo é uma análise de uma capa da revista americana Time, edição de 16 de abril de 2003. Através da intertextualidade e interdiscursividade, a revista associava o presidente do Iraque, Saddam Hussein, a Adolf Hitler. É um artifício recorrente do discurso midiático, que consiste em identificar os acontecimentos ou personagens públicos no plano simbólico através da memória coletiva.

PALAVRAS-CHAVE: semiótica; memória coletiva; Guerra do Iraque

ABSTRACT: This article is an analysis of the cover of the American magazine Time, April 16th 2003 issue. Through intertextuality and interdiscursivity, the magazine associated the Iraqi president, Saddam Hussein, to Adolph Hitler. This is a strategy widely used in the media discourse: it consists of identifying public events or characters in a symbolic plan through the use of the collective memory.

KEYWORDS: semiotics; collective memory; War in Iraq 


\section{Pressupostos teóricos}

A análise proposta neste artigo está relacionada a uma capa da revista americana Time, edição de 16 de abril de 2003. Por sua especial singularidade, a capa chama a atenção de imediato, uma vez que organiza um campo semântico fecundo. No entanto, antes de avançar para o objeto de análise, é preciso apontar - ainda que brevemente - alguns marcos teóricos que servem de referência.

Roland Barthes em Elementos de semiologia afirmou que qualquer sistema de significação comporta um plano de expressão (E) e um plano de conteúdo (C) e que a significação coincide com a relação (R) entre os dois planos: E R C. A significação pode ser concebida como um processo: é o ato que une a expressão e o conteúdo (BARTHES, 2001). No estudo aqui proposto, é feita a substituição da tradicional denominação do corte saussureano (signo, significado e significante) pela função semiótica, expressão e conteúdo, utilizando a terminologia cunhada por Louis Hjelmslev (Barthes, 2001; Fabri, 2000; Zunzunegui, 1998).

A relação de expressão e conteúdo apontada por Barthes é estabelecida na análise sob a forma de um texto midiático (uma capa), instaurado no interior do processo comunicativo que o criou. Esse processo comunicativo, especificamente, não consiste em "dizer qualquer coisa", nem em estatuir sobre o "estado das coisas", mas em tentar convencer, de uma ou de outra maneira, seu interlocutor (Greimas, 1998, c.1980:122). Trata-se de um fazer persuasivo que consiste "na convocação, pelo enunciador, de todo tipo de modalidades com vistas a aceitar, pelo enunciatário, o contrato enunciativo proposto e tornar, assim, eficaz a comunicação" (Santaella, 2004:115).

O conceito de texto apresentado no parágrafo anterior pode ser entendido como um signo (que pode ser composto de outros signos), que produz(em) sentido, porém esse sentido não é obtido simplesmente pela soma dos significados parciais dos signos que compõem o texto, mas por suas relações textuais. No caso da capa, a coerência textual deve ser entendida como um elemento expressivo, uma vez que distribui a informação visual, e como um elemento de conteúdo, na medida em que autoriza a atualização de seu significado por parte do destinatário do discurso visual (Zunzunegui, 1998:78). Os textos em sua ocorrência são estruturas materiais, dotadas de uma morfologia, de uma funcionalidade e de uma forma exterior identificável (plano de expressão), cujo conjunto é destinado a um uso ou a uma prática (plano de conteúdo). Cada texto midiático é inseparável da sua relação com outros textos e discursos que lhe atribuem sentido, ou seja, o contexto semiótico no qual está inserido e que, dessa forma, lhe confere eficácia enunciativa e pragmática (Fontanille, 2005).

Quando se utiliza a expressão texto em vez de signo, faz-se uma escolha relativa ao nível de pertinência da análise e, de certa forma, amplia-se o próprio conceito de texto, compondo assim uma textualidade. Aqui, o objeto de análise é uma capa. E esta, por sua vez, é parte de uma edição, ou seja, de uma estratégia textual mais ampla.

\section{A CAPA}

O dia 11 de setembro de 2001 ficou marcado por uma série de ataques terroristas em território norte-americano. Em Washington, um avião chocou-se com prédio do 
Pentágono. Em Nova York, dois aviões destruíram as torres gêmeas do World Trade Center, provocando a morte de cerca de 3 mil pessoas. Imediatamente houve uma retaliação militar e os Estados Unidos iniciaram uma invasão no Afeganistão em outubro do mesmo ano. A milícia Talibã, que governava o país, era acusada de apoiar diretamente a organização terrorista $\mathrm{Al}$ Qaeda, que reivindicou a autoria dos atentados. Acreditava-se que o líder da organização, o saudita Osama Bin Laden, estava escondido nas montanhas de Tora Bora, ao sul do Afeganistão. As cidades em poder dos talibãs foram ocupadas gradualmente e em novembro a capital Cabul foi dominada pelas forças norte-americanas e da Aliança do Norte.

Em março de 2003 o Iraque também seria invadido por uma coalizão formada por Estados Unidos, Inglaterra, Espanha e Austrália, dando continuidade à política internacional de luta contra o terrorismo. A invasão foi divulgada pela mídia internacional como uma espécie de "guerra preventiva” contra Saddam Hussein (na época, presidente do Iraque). As razões apontadas para a guerra foram bastante variadas: Saddam Hussein era considerado um ditador "diabólico" - era rico, agressivo e repressivo; organizou a invasão e a anexação de um Estado membro da ONU (o Kuwait, em 1991) e implacavelmente massacrou a própria população; estava trabalhando obstinadamente para conseguir armas de destruição em massa e, quando isso acontecesse, estaria preparado para usá-las; provocou massacres com armas químicas na minoria curda; e, finalmente, era acusado de apoiar a organização terrorista Al Qaeda (Knightley, 2004:527-528). A primeira fase da invasão durou cerca de um mês, de 20 de março a 15 de abril de 2003. Apesar da resistência iraquiana em algumas cidades, o regime iraquiano sucumbiu rapidamente.

Na edição de 21 de abril de 2003, uma semana após o fim da primeira fase da guerra, a revista americana Time publicou uma série de matérias relacionadas ao conflito: notas sobre o antigo regime iraquiano, a situação das tropas aliadas no país, a vida no Iraque pós-Saddam Hussein, especulações sobre quem seria o sucessor do antigo ditador, etc. Além desses assuntos, a capa da revista chamava a atenção por uma série de detalhes (fig. 1).

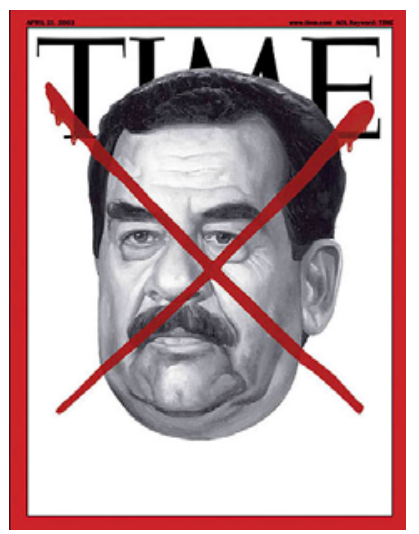

Fig. 1: Capa da revista Time, de 21 de abril de 2003. 
Este texto ilustrativo apresenta uma reduzida gama de cores que compõem a capa: vermelho, branco, preto e tons de cinza. O retângulo vermelho que serve como moldura e o fundo branco destacam e recortam todos os outros elementos. Não há nenhum título de chamada, exceto a palavra "TIME", parcialmente encoberta pela testa e pelos cabelos do rosto de um homem. Este apresenta-se virado à esquerda do observador na posição de 3/4; não há pescoço. Trata-se da ilustração de um homem de certa idade, provavelmente entre os 60 e 65 anos. Destacam-se as formas arredondas do seu rosto (que quase toma a capa inteira), as sobrancelhas e o bigode espessos. Apesar dos traços e linhas proeminentes que atestam a sua idade, a expressão dos olhos e da boca não revela qualquer tipo de sentimento, seja alegria, tristeza ou raiva. Finalmente, um " $X$ " vermelho atravessa a ilustração do rosto e também as letras " $T$ " e "E" da palavra "TIME". O efeito da ilustração simula tinta fresca, ainda escorrendo. O homem dessa capa é o antigo presidente do Iraque, Saddam Hussein.

Na página 8 daquela edição, havia uma pequena nota intitulada "When regimes get the " $X$ "1 . Nela, a revista explicava claramente ao leitor o porquê da capa da edição de 2003 (com o rosto de Saddam Hussein). Tal capa era na verdade uma alusão a uma capa mais antiga, publicada em 1945, ano que terminou a Segunda Guerra Mundial. Naquele ano, havia uma série de rumores sobre o que havia acontecido com Adolf Hitler, o führer do regime nazista: ele havia sido capturado pelo chefe da Gestapo, Heinrich Himmler; havia fugido para o Japão; tinha sido morto por uma granada ou bomba. Porém, o que era tido como certo era que Berlim, capital da Alemanha e sede do regime nazista, estava derrotada pelas forças aliadas. Afirmava-se que "Adolf Hitler foi enterrado, morto ou vivo, nos destroços do seu desmoronante III Reich”. A revista Time não sabia o que poderia ter acontecido com Hitler, mas tinha certeza de que o seu governo havia terminado. Assim, publicou uma série de matérias sobre o fim da Segunda Guerra Mundial (1939-1945). A capa da edição de 21 de maio de 1945 está reproduzida abaixo (fig. 2).

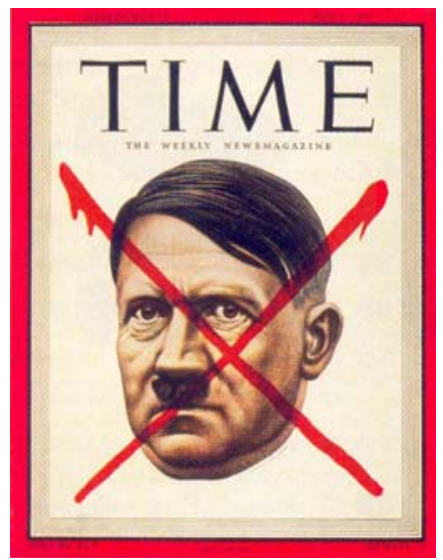

Fig. 2: Capa da revista Time, de 21 de maio de 1945.

Três retângulos servem de moldura para a capa da revista. O primeiro, mais externo, é vermelho; o segundo, preto e fino. Finalmente, o terceiro é formado por um 
conjunto de linhas finas e pretas que, próximas umas das outras, criam um efeito de cinza emoldurando o fundo branco. Não há nenhuma chamada de matérias ou de assuntos, apenas o nome da revista - "TIME" - e logo abaixo "The weekly newsmagazine”. Praticamente no centro, encontra-se a ilustração colorida do rosto de um homem sem pescoço. Ele está à esquerda do observador na posição de $3 / 4$. Os cabelos são lisos e penteados para o lado, mas são curtos próximo à orelha, lembrando um estilo de corte militar. O bigode é pequeno, incompleto, e praticamente acompanha o tamanho do nariz. Embora esteja com o rosto parcialmente virado, os olhos estão voltados para o observador e apresentam (junto com a boca) uma expressão severa, instigante e grave, quase ameaçadora. Pelos traços, esse homem tem entre 50 e 60 anos. Finalmente, um " $X$ ” vermelho atravessa a ilustração do rosto, com um efeito que simula tinta fresca, ainda escorrendo. O homem dessa capa é Adolf Hitler, o führer do regime nazista.

De fato, é difícil duvidar: a capa da revista de 2003 com Saddam Hussein remete por semelhança à capa de 1945, com Adolf Hitler. Um texto dialoga com outros textos em duas relações: de intertextualidade e de interdiscursividade. A primeira diz respeito às referências de um texto a outros textos, tanto no plano da expressão quanto do conteúdo; a interdiscursividade representa as pontes que um determinado texto constrói com o seu contexto histórico e cultural. “A intertextualidade é o processo de incorporação de um texto em outro, seja para reproduzir o sentido incorporado, seja para transformá-lo. Há de haver três processos de intertextualidade: a citação, a alusão e a estilização” (Fiorin, 1994:30). O processo de citação carrega a expressão e o conteúdo do texto citado e mantém uma forte relação referencial entre os textos. Já na alusão, os planos da expressão e do conteúdo permanecem semelhantes, mas a relação referencial entre textos é mediana. A estilização é um processo de intertextualidade mais fraco, em que sobrevive apenas uma impressão, ou procedimento genérico, do estilo do texto que remete.

Nos contextos desta análise, intertextualidade e interdiscursividade só ganham sentido na medida que a revista Time deixou explícito para o leitor a sua escolha para a capa da edição de 2003. E isto foi feito na nota de página daquela edição, intitulada "When regimes get the " $X$ ", citada anteriormente. Ali, a revista explicava que Saddam Hussein não é Adolf Hitler, mas seus regimes de governo (personificados na figura dos ditadores) são semelhantes. É a revista Time que estabelece (e lembra) para o leitor as semelhanças entre os acontecimentos de 2003 e 1945. Por acreditar em tais semelhanças, a revista publicou a capa com o rosto de Saddam Hussein em alusão a Adolf Hitler. A alusão interdiscursiva “[...] ocorre quando se incorporam temas e/ou figuras de um discurso que vai servir de contexto (unidade maior) para a compreensão do que foi incorporado" (Fiorin, 1994:34).

Porém, existe um segundo fenômeno intertextual - embora não tão evidente ou explícito (estilização) - nos textos ilustrativos da análise. Se uma capa faz alusão a outra, ambas remetem a uma referência bastante antiga e de certa forma muito popular à cultura norte-americana: os cartazes de bandidos procurados do Velho Oeste. Tais cartazes, que podiam variar de tamanho, forma e estilo, eram feitos para serem fixados em lugares públicos e de grande circulação nas cidades. Eles serviam para identificar os procurados pela lei por meio de uma fotografia ou ilustração. A descrição dos principais crimes, às vezes acompanhada de supostas declarações do procurado, indicava seu grau 
de periculosidade. Além disso, era comum destacar a quantia em dinheiro que seria paga como recompensa, caso houvesse a captura.

Considerando o que foi apresentado anteriormente, apontamos algumas conotações possíveis para os elementos da capa da edição de 2003 da Time:

a) $o$ " $X$ ”. Ele conota uma simbologia do /fim/, indicando referencialmente que aquele que antes existia ou atuava de alguma forma, não existe mais, ou seja, encontrou o /fim/;

b) o vermelho do " $X$ ”. Está relacionado a /atenção/ e /perigo/, como os sinais de trânsito e alertas de incêndio, ou seja, ele capta de modo eficaz a atenção;

c) a tinta vermelha escorrendo. Ela reforça uma situação ou ação que foi recentemente concluída e finalizada: é a /instantaneidade/, o /presente/;

d) o rosto de Saddam Hussein. Ele aponta para /identificação/, /individualização/, /singularidade/, /nomeação/ e /qualificação/, uma vez que o rosto é o elemento mais expressivo do corpo humano;

e) o tamanho do rosto. Ele está destacado em relação ao fundo branco da revista, é grande e cobre as letras da palavra "TIME”. O efeito provocado sugere uma idéia, um movimento ou uma sensação de /expansão/, /crescimento/, /aumento/;

f) a ilustração faz uma alusão a outra capa publicada em 1945, com Adolf Hitler. Através da semelhança nas ilustrações, sugere-se que existe no nível do conteúdo alguma identificação, similaridade ou proximidade entre as duas pessoas ilustradas;

g) ambas as capas (embora em um nível mais distante, com já foi frisado) remetem para uma referência antiga e popular à cultura norte-americana: os cartazes de /bandidos/ /procurados/ do Velho Oeste.

\section{REFLEXÕES}

As primeiras conotações a que a capa remete (letras “a”, "b” e “c”) já foram apresentadas anteriormente. Ou seja, mesmo sem a captura do antigo presidente, a revista Time previu que o seu regime havia terminado durante a primeira fase da invasão $^{2}$. De certo modo, a previsão estava correta: o regime sucumbiu à invasão, porém - e aqui encontra-se um paradoxo - isso não significou a vitória plena.

Ainda no ano de 2003, já era possível identificar vários indícios de que a democratização imposta ao Iraque pela coalizão não dependeria apenas da remoção de Saddam Hussein do poder. As denúncias de torturas e espancamentos de iraquianos na prisão de Abu Ghraib (2004) já eram um sinal de que a campanha militar americana estava enfrentando problemas. Após a invasão, a crise no Iraque, provocada pelas insurgências xiita e sunita, além de vários conflitos políticos internos, aponta para um agravamento da situação social no país. Somam-se a isso o elevado número de baixas americanas (mais de 4 mil) e a longa duração do conflito (quase seis anos), que de modo direto têm pressionado a política e a opinião pública norte-americana para uma rápida solução da guerra. Como já foi dito, o fim do regime não significou a paz.

O uso do rosto de Saddam Hussein, conforme foi apontado nos itens "d" e "e", remete para uma individualização/personalização do conflito. Em alguns momentos, o 
uso do rosto ajudou a situar simbolicamente a Guerra do Iraque apenas na figura de Saddam Hussein, ou seja, ele seria o único alvo (Griffin, 2004; Knightley, 2004).

Os discursos midiáticos normalmente têm uma necessidade de identificar “inimigos” sociais, de mostrar o seu rosto e, se possível, de associar a eles certas responsabilidades, principalmente em momentos de crise social. Essa característica do discurso midiático apresenta-se em várias situações (ou enunciados): "o chefe do tráfico é...”, “o líder do movimento é...”, “quem mandou fazer foi...”, etc. No caso da capa em análise, essa personalização também está associada (embora não seja explícito) aos cartazes do Velho Oeste, e eles dizem: "Vejam! Este é o bandido procurado".

O nível de personalização na Guerra do Iraque foi alto, e um exemplo disso é o fato de que, durante o ano de 2003, Saddam Hussein foi capa da revista Time em quatro edições, e em todas o seu rosto aparecia em destaque (fig. 3 ).
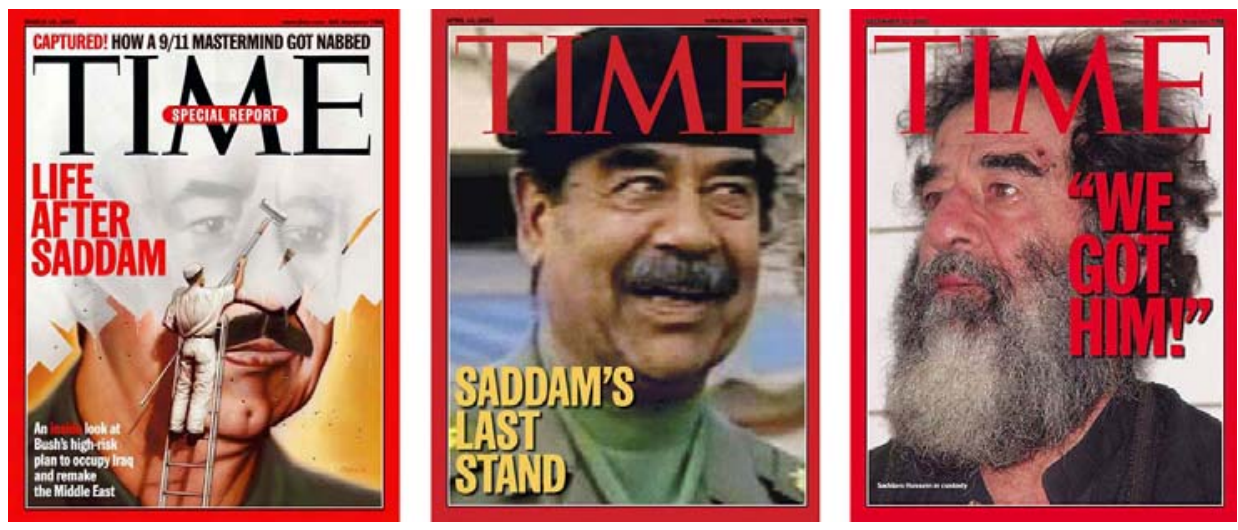

Fig. 3: rosto de Saddam Hussein nas capas da revista Time durante o ano de 2003.

A personalização do conflito permitiu o surgimento de dicotomias antagônicas que revelavam oposições de idéias, rivalidades ou incompatibilidades diversas. Conforme alguns autores (Andersen, 2006; Kellner, 2004; Knightley, 2004; Snow \& Taylor, 2006), dos atentados de 11 de setembro de 2001 até os meses que antecederam a invasão do Iraque (final de 2002 e início de 2003), houve uma predominância nos discursos da grande mídia americana em apresentar a guerra que se aproximava como uma espécie de “caçada a um ditador”, no caso, Saddam Hussein. Tais discursos procuravam situar a guerra apenas como um embate entre dois líderes, George W. Bush e Saddam Hussein, ou seja, tratava-se de uma personalização e individualização do conflito capaz de aglutinar em torno de si idéias, discursos e/ou visões de mundo abstratas, amplas, genéricas e muitas vezes ambivalentes, simplistas e purgadas de toda complexidade (Andersen, 2006; Knightley, 2004; Griffin, 2004).

Um exemplo foi o surgimento de dicotomias antagônicas associadas coletiva e simbolicamente aos líderes citados e que revelavam uma série de idéias opostas, rivalidades ou incompatibilidades diversas. Melhor: a Guerra do Iraque, representada unicamente na figura dos líderes, significava também o grande embate entre "o Bem e o Mal”, “a Civilização e a Barbárie”, “o Ocidente e o Oriente”. 


\begin{abstract}
As simples dicotomias da guerra entre o bem e o mal rapidamente emergiram quando o presidente convocou a comunidade mundial a escolher entre a civilização e o terrorismo ${ }^{3}$. Uma corrente forte de vozes enquadrou a "nova guerra" como uma luta de valores entre o bem e o mal, entre a liberdade e "nosso modo de vida". Sentindo que era impossível se opor a tais ideais abstratos, poucos se sentiram à vontade para expressar algum protesto contra a "liberdade", "democracia" e os "nossos valores civilizados", especialmente após a violação da soberania americana. Tal retórica encerrou o debate, bem como suas dimensões políticas e suas complexidades. Não haveria nenhum debate aberto sobre a política externa americana, principalmente sobre o Oriente Médio, e especialmente no mainstream media (Andersen, 2006:202).
\end{abstract}

Além de identificar a fonte de todo o mal (Saddam Hussein), a idéia da mídia americana (e, de certo modo, de uma parte da mídia ocidental) foi enfatizar os perigos do regime iraquiano, o que assumiu contornos de uma criação e manutenção de um medo coletivo, de uma ameaça permanente. Duas estratégias são reconhecidas: a primeira foi ligar constantemente o governo iraquiano a todo tipo de extremismo (como a rede terrorista $\mathrm{Al}$ Qaeda e a ameaça de armas de destruição em massa); a segunda consistia em utilizar a memória coletiva. Vejamos um exemplo da primeira estratégia.

Michael Griffin, comparando a cobertura fotojornalística da Guerra do Iraque em três revistas americanas (Time, Newsweek e US News \& World Report), concluiu que, antes de a guerra começar, as matérias referentes ao regime iraquiano eram normalmente acompanhadas de matérias sobre o terrorismo, reforçadas com fotografias de impacto de Osama Bin Laden, dos ataques ao World Trade Center (2001), dos massacres aos curdos com armas químicas, entre outras. Além disso, as fotografias do povo iraquiano eram normalmente associadas a símbolos de violência (como crianças brincando com armas e guerreiros fedayeen ${ }^{4}$ ) e também de fanatismo religioso (demonstrações públicas de fervor, como passeatas). Conforme o autor, tais referências eram uma maneira de identificar um inimigo que de fato era desconhecido dos americanos e ligá-lo a situações que permaneciam vivas na memória, como o terrorismo (Griffin, 2004).

No entanto, conforme já citado, a criação do medo coletivo também estava ligada a uma outra estratégia: o uso da memória coletiva como uma forma eficiente de mensagem persuasiva (conotação apontada no item “f”). Maurice Halbwachs determinou que a memória é uma atividade fundamentalmente social, realizada não na privacidade de uma inteligência particular, mas em uma consciência partilhada que influencia as agendas daqueles que a evocam. A memória coletiva é uma ferramenta não de recuperação, mas de reconfiguração, que coloniza o passado por obrigá-lo a se conformar às configurações do presente. Ela atua como uma espécie de "história em movimento", movendo-se numa freqüência e num passo diferentes da história tradicional e florescendo no refazer do passado que ressoa contemporaneamente (Zelizer, 1999:99).

Um exemplo. No livro The threatening storm: the case for invading $\operatorname{Iraq}^{5}$, publicado em setembro de 2002, Kenneth Pollack, ex-analista da CIA, comparava a ameaça representada por Saddam Hussein à de Adolf Hitler na década de 1940. Saddam Hussein estaria adquirindo a capacidade de matar milhões de pessoas (com o uso de armas de destruição em massa) e também de dominar a economia mundial, uma vez que 
o Iraque possui grandes reservas de petróleo. O ditador, para o autor, seria a encarnação do Mal extremo e absoluto.

É importante ressaltar que não era a primeira vez que o discurso midiático ligava Saddam Hussein a Adolf Hitler. Elihu Katz (1992) no importante ensaio The end of journalism? Notes on watching the war relata situação semelhante durante a Guerra do Golfo Pérsico em 1991. Desde o início percebeu-se que aquela guerra deveria ser enquadrada de uma forma diferente. As guerras da Koréia, Vietnã e na América Central foram “empacotadas” como guerras ideológicas com a intenção de diminuir a ameaça comunista. Contudo, na época da Guerra do Golfo Pérsico, enquadrar os conflitos na perspectiva da Guerra Fria não era mais possível.

O presidente George H. Bush sugeriu então a Segunda Guerra Mundial como um modelo para a confrontação com o Iraque, e a mídia seguiu o exemplo. O Iraque havia engolido um país vizinho, desafiando sua legitimidade e independência. O Iraque era a Alemanha fascista cometendo genocídios contra suas minoriais; Saddam Hussein era Hitler, a personificação do mal. O exército iraquiano era o quarto maior do mundo, completado com armas de destruição em massa. Isto não era uma confrontação de ideologias, era uma cruzada moral do bem contra o mal. A vitória total era um prérequisito para a sobrevivência da civilização ocidental (Katz, 1992:6).

Em relação à Guerra do Golfo Pérsico em 1991, Douglas Kellner também observa:

A satanização de Hussein e dos iraquianos era importante porque, se eles fossem absolutamente maus e constituíssem uma ameaça idêntica à de Hitler e dos nazistas, nenhuma negociação seria possível, e estaria excluída qualquer possibilidade de solução diplomática para a crise (Kellner, 2001:265).

A questão do uso da memória coletiva como uma ferramenta valiosa do poder político é muito relevante. Embora muitos autores tenham se dedicado ao assunto, como Tzvetan Todorov e Andreas Huyssen, também se destacam as reflexões de Bronislaw Baczko e Hanna Arendt. Baczko demonstrou que qualquer poder designadamente político está rodeado de representações coletivas, imaginários, usos do passado e da memória. Para o poder, o domínio do simbólico é um lugar importante, vital e estratégico. "Quando uma coletividade se sente agredida pelo exterior, ela põe em marcha, como meio de autodefesa, todo seu dispositivo imaginário, a fim de mobilizar as energias dos seus membros, unindo e guiando as suas ações” (Baczko, 1988:310). Qualquer poder procura desempenhar um papel privilegiado na emissão dos discursos que veiculam os imaginários sociais, do mesmo modo que tenta conservar um certo controle sobre os circuitos de difusão. As principais instituições encarregadas de disseminar tais discursos são o Estado e a imprensa.

No caso da Guerra do Iraque, as funções do uso desses imaginários e passados (perigos de armas nucleares, totalitarismos, violência, Al Qaeda, Adolf Hitler, as lembranças do Holocausto, etc.) são múltiplas: designar e nomear o inimigo no plano simbólico de modo que seja facilmente identificável (o discurso da revista Time sugere que Saddam Hussein tem alguma semelhança com Hitler); mobilizar energias e representar as solidariedades; cristalizar e ampliar os temores e esperanças difusos. De certo modo, as convergências simbólicas construídas pelos discursos midiáticos 
contribuíram para a legitimação do uso da violência por parte do Estado americano e de seus aliados.

É preciso destacar mais uma vez que na edição de abril de 2003, a revista Time explicou aos leitores que havia semelhanças entre Saddam Hussein e Adolf Hitler (na nota de página que a revista publicou, citada anteriormente). E também lembrou os acontecimentos de 1945 e a capa da revista naquele ano. Sem este detalhe, nenhuma das reflexões ou contextualizações anteriores teria sentido, uma vez que seria muito difícil (embora não impossível) que algum leitor conseguisse lembrar da capa de 1945 e fazer todas as associações.

Assim, a capa da edição de 2003 tinha uma conotação ampla: o regime liderado por Saddam Hussein (“o bandido procurado”) havia recentemente terminado, a ameaça que se desenvolvia, como no antigo regime nazista, não existe mais. Aqui, voltamos a Greimas: todo ato de comunicação tem a intenção de ser persuasivo, de convencer, e a imagem tem um poder muito forte neste sentido. No exemplo analisado, uma capa faz alusão a um discurso preexistente a ela - intertextualidade. E também apresenta ligações com um amplo contexto histórico e cultural que cerca a guerra - interdiscursividade.

\section{CONCLUSÃo}

A intertextualidade e a interdiscursividade discutidas neste artigo são artifícios do discurso midiático que pretende identificar e nomear os acontecimentos e/ou personagens públicos no plano simbólico através memória coletiva. O campo semântico construído no texto da capa analisada contribuiu para identificar, individualizar e caracterizar um inimigo no plano simbólico e ligá-lo a situações que permaneciam vivas na memória coletiva (o Holocausto, Adolf Hitler).

\section{NotAs}

\footnotetext{
${ }^{1}$ Tradução livre: Quando os regimes ganham um “X”.

2 Saddam Hussein seria capturado no dia 13 de dezembro de 2003, num esconderijo próximo à cidade de Tikrit. Ele foi enforcado em Bagdá no dia 30 de novembro de 2006.

${ }^{3}$ A autora se refere às declarações do presidente americano George W. Bush em 29 de janeiro de 2002 no Estado da União. Os três pontos principais da doutrina "Global War on Terror" são: 1) caçar os terroristas onde quer que eles estejam, incluindo os países classificados como "o eixo do mal”; 2) travar guerras preventivas para evitar futuros ataques à América e também não permitir que armas de destruição em massa (WMD) caiam nas mãos de terroristas; 3) e, finalmente, a promoção agressiva da democracia de estilo americano. As declarações de Bush também determinavam uma divisão radical entre aqueles que apoiavam a guerra e aqueles que eram contra (“you are either with us or against us"), o que transformava qualquer opositor, diplomático ou não, em inimigo (Snow \& Taylor, 2006:392).

${ }^{4}$ Violenta milícia que era liderada por Uday, filho de Saddam Hussein.

${ }^{5}$ Tradução livre: A tempestade ameaçadora: o caso para invadir o Iraque. Ver: POLLACK, Kenneth. The threatening storm: the case for invading Iraq. New York: Random House, 2002.
} 


\section{REFERÊNCIAS BIBLIOGRÁFICAS}

ANDERSEN, Robin. A century of media, a century of war. New York: Peter Lang Publishing, 2006.

BACZKO, Bronislaw. "Imaginação Social”. In: Enciclopédia Einaudi, vol. 5, Antrhopos-Homem. Porto: Imprensa Nacional, 1988:296-332.

BARTHES, Roland. Elementos de Semiologia. São Paulo: Editora Cultrix, 2001.

DUARTE, Elizabeth Bastos. Foto \& grafias. São Leopoldo: Editora Unisinos, 2000. . Televisão: ensaios metodológicos. Porto Alegre: Sulina, 2004.

FABRI, Paolo. El giro semiotico. Barcelona: Gedisa, 2000.

FIORIN, J. L. "Polifonia textual e discursiva”. In: BARROS, D. L. P.; FIORIN, J. L. (Org). Dialogismo, polifonia e enunciação. São Paulo: Edusp, 2004.

FONTANILLE, Jacques. Significação e visualidade - exercícios práticos. Porto Alegre: Sulina, 2005. (Estudos sobre audiovisual; v.3)

GREIMAS, Algirdas Julien. “A propósito do jogo”. Verso\&Reverso, São Leopoldo, Unisinos, Ano XII, n. 27, jul/dez 1998, p.119-123. (Texto original: GREIMAS, A. J. “A propos du jeu”. Actes Semiotiques - Documents, II, 13, Paris: 1980)

GRIFFIN, Michael. "Picturing america's 'War on Terrorism' in Afghanistan and Iraq". Journalism, vol. 5, n. 4, p.381-402, 2004.

[online] Disponível na Internet via WWW.URL:

http://ics.leeds.ac.uk/papers/pmt/exhibits/2052/photo.pdf Arquivo acessado em abril 2006.

HJELMSLEV, Louis. Prolegômenos a uma teoria da linguagem. São Paulo: Perspectiva, 1975.

KATZ, Elihu. "The end of journalism? Notes on watching the war". Journal of Communication, vol. 42, n. 3, p.5-13, 1992.

KELLNER, Douglas. “A Guerra do Golfo: uma leitura”. In: KELLNER, Douglas. A cultura da mídia. Bauru, SP: EDUSC, 2001.

. "Espetáculo e propaganda da mídia na guerra contra o Iraque”. Líbero, Ano VII, n $\mathrm{n}^{\mathrm{o}}$ 13/14, p.65-71, jan. 2004.

KNIGHTLEY, Phillip. The first casualty: the war correspondent as hero and mythmaker from the Crimea to Iraq. Baltimore: The Johns Hopkins University Press, 2004.

SANTAELLA, Lúcia \& NÖTH, Winfried. Comunicação e semiótica. São Paulo: Hacker Editores, 2004. (Coleção Comunicação \& Comunicação)

SNOW, Nancy \& TAYLOR, Philip M. "The revival of the propaganda state. US propaganda at home and abroad since 9/11". The International Communication Gazette, vol. 68, n 5-6, p. 389-407, 2006.

ZELIZER, Barbie. "From the image of record to the image of memory: Holocaust photography, then and now". In: BRENNEN, Bonnie; HARDT, Hanno (eds.). Picturing the past: media, history and photography. Chicago: University of Illinois Press, 1999.

ZUNZUNEGUI, Santos. Pensar la imagem. Madri: Ediciones Cátedra - Universidad del País Vasco, 1998. 


\section{Como citar este artigo:}

FURTADO, Orleãs Alan Mendonça. O rosto de Saddam Hussein: um estudo de caso. Estudos Semióticos. [online] Disponível na Internet via WWW.URL: http://www.fflch.usp.br/dl/semiotica/es. Editor Peter Dietrich. Número 4, São Paulo, 2008. Acesso em "dia/mês/ano". 